\title{
The influence of creatinine, lecithin and choline feeding on aliphatic amine production and excretion in the rat
}

\author{
By SUSAN LOWIS, M. A. EASTWOOD* AND W. G. BRYDON \\ Wolfson Gastrointestinal Laboratory, Gastrointestinal Unit, Department of Medicine, \\ Western General Hospital, Edinburgh EH4 $2 X U$
}

(Received 16 July 1984 - Accepted 6 February 1985)

1. The excretion of aliphatic amines, methylamine, dimethylamine and trimethylamine in the urine and faeces of rats fed on a control diet and diets supplemented with creatinine, lecithin or choline were measured over a $14 \mathrm{~d}$ feeding period.

2. The rats were then killed and concentrations of amines in small and large intestinal contents measured.

3. Adding creatinine to the diet resulted in a significant increase of methylamine excretion in the faeces and urine. The amount of methylamine found in all parts of the intestine increased, especially in the caecum.

4. Adding lecithin to the diet resulted in an increase in the methylamine excretion only, and no change in the concentrations of amines found in the intestine, except for trimethylamine which was significantly increased in the caecum and colon.

5. Adding choline to the diet resulted in a significant increase in excretion of trimethylamine and, to a lesser extent, methylamine. The levels of amines found in the gut increased, dimethylamine being increased in the small bowel, and methylamine and trimethylamine in the caecum.

The aliphatic amines, methylamine (MMA), dimethylamine (DMA) and trimethylamine (TMA) are produced from creatinine, lecithin and choline by bacterial metabolism in the gut, and are excreted in the urine and faeces (Asatoor \& Simenhoff, 1965). A suggested scheme of metabolism is given in Fig. 1.

Endogenous production of creatinine arises as a result of muscle creatine breakdown and exogenous creatinine is derived mainly from dietary meat. Serum levels are affected by renal function and dietary meat intake (Watson et al. 1981; Mayersohn et al. 1983). A proportion of dietary creatinine passes to the caecum (Dominguez \& Pomerene, 1951) and creatinine in serum can cross the ileal wall and pass to the caecum (Jones \& Burnett, 1974). Lecithin arises endogenously in bile and exogenously from dietary fish and eggs. Choline is mostly found incorporated in lecithin (Wurtman, 1979; Akesson, 1982).

The major amine excreted in urine is DMA, which is produced by demethylation of TMA or methylation of MMA (Asatoor \& Simenhoff, 1965). The aliphatic amines have mainly been studied in subjects with renal failure (Simenhoff, 1975; Simenhoff et al. 1978), hepatic failure (Marks et al. 1979) and trimethylaminuria (Marks et al. 1977; Spellacy \& Watts, 1980). These reports are incomplete in that not all amines have been measured. Previous work has concentrated on the diseased state and little is known about the normal physiological production and excretion of these amines.

The objectives of the present study were to investigate the normal physiological production and exretion of aliphatic amines and to observe how this was altered by augmenting the diets with creatinine, lecithin or choline.

\section{MATERIALS AND METHODS}

Thirty-two male adult Wistar rats were divided equally into four groups: (1) control (2) creatinine-fed, (3) lecithin-fed, (4) choline-fed rats. The control group was fed on a rat maintenance diet (no. 1; Special Diet Services Ltd, 1 Stepfield, Witham, Essex) which consists of $(\mathrm{g} / \mathrm{kg}) 24$ fat, 136 protein, 186 dietary fibre, 380 starch, 104 sugars and an 


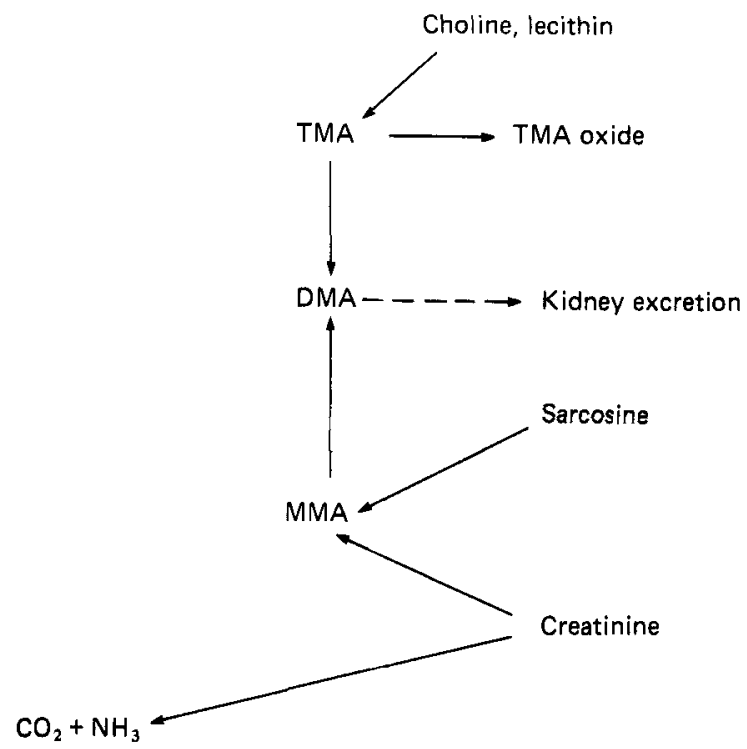

Fig. 1. Suggested scheme of the metabolism of the aliphatic amines methylamine (MMA), dimethylamine (DMA) and trimethylamine (TMA).

adequate supply of minerals and vitamins including choline at $1.4 \mathrm{~g} / \mathrm{kg}$. The lecithin content of the diet was estimated at $0.13 \mathrm{~g} / \mathrm{kg}$. Groups $2-4$ were given the same diet with creatinine, lecithin or choline added at $20 \mathrm{~g} / \mathrm{kg}$ diet. Before the experiment the rats were fed on a Spratts laboratory small animal diet (Barking, Essex).

The rats were weighed before commencing the experimental or control diets and again just before being killed. Each group of rats was fed ad lib. for $14 \mathrm{~d}$ on the control and supplemented diets, during which time urine and faeces were collected separately by placing the rats in individual metabolism cages for $24 \mathrm{~h}$. Urine and faeces were collected on day 0 (when rats were fed on a Spratts diet), and days 3, 7,10 and 14 (when rats were fed on the control or supplemented diets). Both urine and faeces were collected in containers acidified with $1 \mathrm{M}$-hydrochloric acid to trap amines as hydrochlorides.

On day 15 the rats were killed by diethyl ether anaesthesia and contents from the upper small bowel, lower small bowel, caecum and large bowel were collected separately into $5 \mathrm{ml}$ portions of $1 \mathrm{M}-\mathrm{HCl}$.

The acidified faeces and intestinal contents were mixed for $0.5 \mathrm{~min}$ and centrifuged at $1600 \mathrm{~g}$ for $5 \mathrm{~min}$. This procedure was repeated with another four $5 \mathrm{ml}$ portions of $1 \mathrm{M}-\mathrm{HCl}$. All the supernatant fractions were pooled and stored at $-20^{\circ}$ until analysed. Acidified urine was stored unmodified at $-20^{\circ}$. The amounts of each amine in the control and supplemented diets were measured. The amines were extracted into $1 \mathrm{M}-\mathrm{HCl}$ and measured by treating the food in the same manner as faeces.

The amines in urine, faeces and intestinal contents were analysed by a gas-liquid chromatographic head-space analysis technique (Lowis et al. 1983). All samples were analysed in duplicate and a new calibration graph was drawn each day. Urinary creatinine excretion $(24 \mathrm{~h}$ ) was determined for control and creatinine-fed rats (Technicon Instruments Co. Ltd, 1970).

The Wilcoxon test for paired samples and for a continuous population was used to assess the differences between groups. 
Table 1. Concentrations of amines $(\mu \mathrm{g} / \mathrm{g})$ found in the food of each diet

(Values are from a single analysis)

\begin{tabular}{lccc}
\hline \hline Diet & Methylamine & Dimethylamine & Trimethylamine \\
\hline Control & $9 \cdot 2$ & $7 \cdot 4$ & $8 \cdot 1$ \\
Creatinine $(20 \mathrm{~g} / \mathrm{kg})$ & 16.2 & 3.2 & $3 \cdot 7$ \\
Choline $(20 \mathrm{~g} / \mathrm{kg})$ & 6.4 & $5 \cdot 0$ & $73 \cdot 0$ \\
Lecithin $(20 \mathrm{~g} / \mathrm{kg})$ & 6.2 & 4.3 & $5 \cdot 8$ \\
\hline \hline
\end{tabular}

\section{RESULTS}

The rats weighed about $300-400 \mathrm{~g}$ at the start of the feeding regimen (mean $355 \mathrm{~g}$ ) and, at day 14, all rats had gained weight (mean $374 \mathrm{~g}$ ). The rats consumed about $20 \mathrm{~g}$ food/d in their normal cages and $12 \mathrm{~g} / \mathrm{d}$ in their metabolism cages.

Significant quantities of amines were found in the control diet (Table 1). Contamination with amines was small except where $20 \mathrm{~g}$ choline $/ \mathrm{kg}$ were added to the diet, when $73 \mu \mathrm{g}$ TMA/g food were detected.

A large variation in excretion of amines in the rats was found, especially in the choline-fed animals (Table 2). Table 2 shows the results for the urinary excretion of the aliphatic amines during the 14-d feeding period for the four groups of animals. Significance levels, where given, are based on comparison with the control group on the same day. For the controls, DMA was the major free amine excreted, while MMA and TMA were present in smaller, comparable amounts.

On feeding the creatinine-supplemented diet, MMA was significantly increased on all days $(P<0.01)$ and, by day 10 , the increase was approximately 200 -fold. The excretion of DMA and TMA was unchanged throughout the study period. On feeding the lecithin-supplemented diet, MMA excretion was increased significantly on all days, while DMA and TMA showed no significant change. On feeding the choline-supplemented diet, TMA became the major free amine excreted. TMA and MMA excretions were significantly increased on all days $(P<0.01)$ and excretion of DMA was significantly increased on days 10 and 14 $(P<0.01$ and $P<0.05$ respectively).

Results for the excretion of aliphatic amines in faeces during the 14-d feeding period are presented in Table 3 for the four groups of animals. Significance levels, where given, are based on comparison with the control group on the same day.

On the control diet, approximately similar amounts of each amine were excreted. The amounts of MMA and TMA found were similar to those found in urine, while the amount of DMA was much less. On feeding the creatinine-supplemented diet, MMA excretion was significantly increased on all days $(P<0.01)$ and, like urine, this increase was considerable. The excretion of DMA and TMA was unchanged throughout the study period. On feeding the lecithin-supplemented diet, there was a small but significant increase in MMA excretion on all days $(P<0 \cdot 01)$. On feeding the choline-supplemented diet, TMA was significantly increased for all days $(P<0.01)$ as was MMA, except on day 14 when there were large individual variations. There was a small significant increase in DMA excretion on days 10 and $14(P<0.01)$.

In Table 4 the amounts of the amines in the different segments of the intestine are given for the four groups of rats. DMA was found mainly in the small bowel while TMA and MMA were found in the hind-gut, mainly in the caecum.

A significant increase in MMA $(P<0.01)$ was found in all parts of the intestine and colon on feeding creatinine, the largest increase occuring in the caecum. The total amount of MMA 


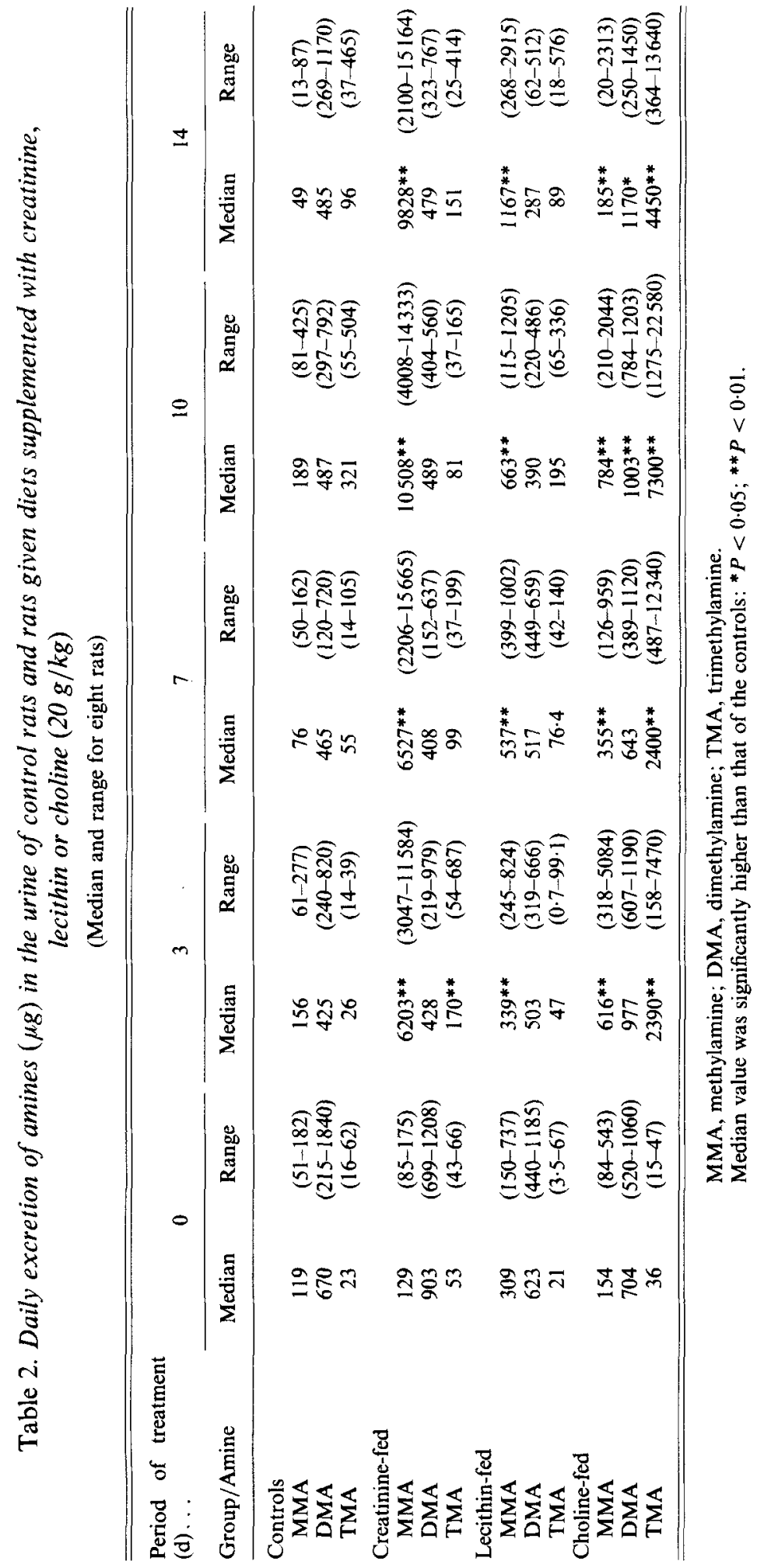




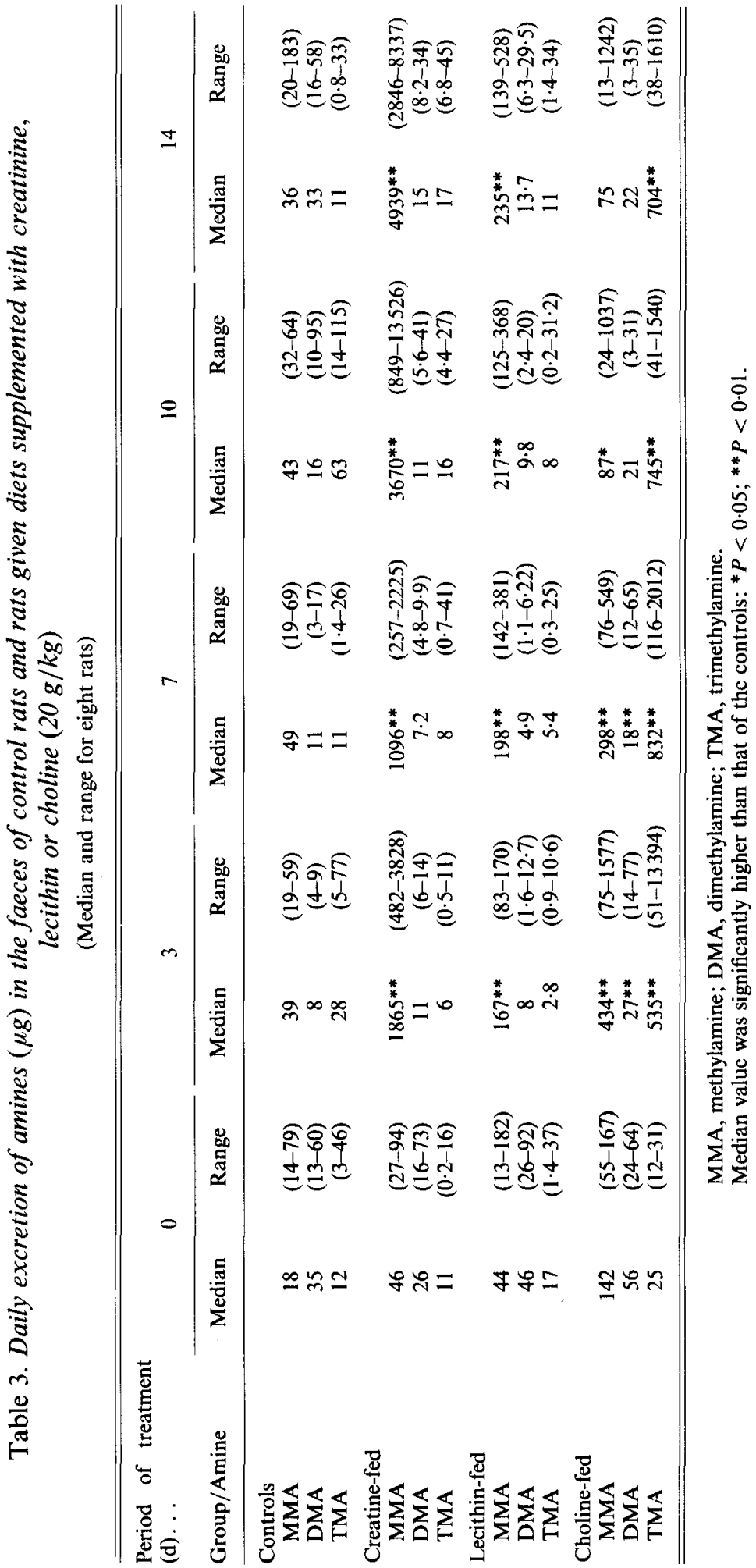


found was about fiftyfold greater in creatinine-fed rats compared with control rats. There were also smaller but significant increases in TMA and DMA $(P<0.01)$ in the caecum. On feeding choline there was a small significant increase $(P<0.01)$ in TMA (all areas), DMA (all areas except colon) and MMA (caecum only). DMA increased mainly in the small bowel, whereas MMA and TMA increased mainly in the caecum. The total TMA found throughout the intestine increased about seventyfold. Lecithin caused a significant increase $(P<0.01)$ in TMA in the caecum only.

The average $24 \mathrm{~h}$ urinary creatinine excretion in rats before creatinine feeding was $2-13 \mu \mathrm{g}$, and during creatinine feeding (at $14 \mathrm{~d}$ ) was $43-148 \mu \mathrm{g}(n 8)$.

\section{DISCUSSION}

The purpose of the present investigation was to measure the production and excretion of aliphatic amines in normal rats fed on a control diet with and without added creatinine, lecithin or choline. The metabolism of these important dietary and biliary constituents in relation to amines has previously been studied mostly in disease states.

In animals fed on the standard control diet, DMA was found to be the major amine excreted in the urine, agreeing with previous work (Asatoor \& Simenhoff, 1965), while MMA and TMA were excreted at similar but much lower rates. All three amines were excreted at similar rates in the faeces. In the intestinal contents, TMA and MMA were found mainly in the caecum and colon while approximately $50 \%$ DMA was found in the upper gut. This is comparable with the results of Simenhofi et al. (1976) who found DMA as the major amine in human intestinal aspirates and suggested that TMA produced in the gut was converted to DMA in the liver and was then, in part, excreted in the bile.

In the present study the variations in amine excretion (Table 2) were very large and may be a reflection of different bacterial populations or enzyme activities of the rat.

Feeding creatinine led to substantial increases in MMA excretion both in faeces and urine but about $60 \%$ of creatinine appeared unchanged in the urine. The daily consumption of creatinine was about $240 \mathrm{mg}$. It has been suggested that $25 \%$ of creatinine eaten by humans passes into the large gut unabsorbed (Mayersohn et al. 1983). Assuming that the same proportion of consumed creatinine passed into the large gut in the rat and was available for bacterial breakdown to MMA, about $19 \mathrm{mg}$ MMA would be formed from total degradation. In the present experiments an approximate increase of $15 \mathrm{mg}$ in the excretion of MMA was seen on feeding creatinine. If these assumptions are correct this would indicate that most of the MMA produced is excreted unmodified. Some absorbed creatinine may pass into the large gut from the blood stream (Dominguez \& Pomerene, 1951) and the additional amount of creatinine this provides for bacterial degradation is unknown.

The absence of an increase in the excretion of dimethylamine in urine and faeces and the similar amounts of DMA found in the intestines of creatinine-fed and control rats would indicate that MMA is not being converted to DMA to any great extent as was found by Asatoor \& Simenhoff (1965); lack of an appropriate methyl donor could explain the absence of increase in DMA. Previously it was suggested that MMA did not cross the colon wall (Dominguez \& Pomerene, 1951). The large excretion of MMA in urine would make this appear unlikely, although this may be concentration-dependent. Some increase in MMA occurs in the upper small intestine on feeding creatinine. This may be due to the increased dietary MMA consumption or accumulation in the enterohepatic circulation of MMA. Using in vitro incubation of gut contents, Jones \& Burnett (1972) could not find 'creatinase' activity in rat caecal contents. The results in the present study show that, on feeding creatinine, the caecum is a major site of MMA formation and so 'creatinase' activity would be expected there. 
Feeding lecithin caused no change in any amine in any part of the intestine. Lecithin is hydrolysed in the small bowel by phospholipase $\mathrm{A}_{2}$. $(E C 3.1 .1 .4)$ producing a free fatty acid and a lysophospholipid. Further degradation in the lumen does not occur and there is no release of free choline for further metabolism (Houstemuller, 1979). The small increase in both TMA found in the caecum and MMA excreted in the urine and faeces in the lecithin-fed rats is probably due to bacterial metabolism of a small amount of unabsorbed lecithin passing through the small bowel to the colon. There was no increase in production or excretion of DMA.

Feeding choline resulted in a large increase in the amount of TMA and MMA found, especially in the caecum and large bowel, suggesting that these are produced there by bacteria, assuming that choline passes through the small bowel to the colon. Previously it has been shown that, on feeding choline to humans with tardive dyskinesia, a fishy smell due to TMA results (Houstemuller, 1979) indicating that the choline has passed to the hind-gut where it is metabolized by bacteria. This is supported by the present results. In choline-fed rats, DMA was increased, particularly in the small intestine, with little increase in the hind-gut. This may be due to enterohepatic circulation of TMA with conversion to DMA in the liver.

The large increase in MMA excretion in both lecithin- and choline-fed rats and its presence in the gut of choline-fed rats was unexpected as DMA was thought to be an end-product of choline metabolism (Asatoor \& Simenhoff, 1965).

The presence of free amines in the supplemented feeds could contribute to the amounts of amines in the various parts of the gut or in the urine. However, the large amounts of amines, particularly in the caecum, indicate that metabolism of precursors occurs here. On the choline diet the rats consumed about $240 \mathrm{mg}$ choline and $1.5 \mathrm{mg}$ TMA/d. About $35 \mathrm{mg}$ of the choline can be accounted for by amine excretion. TMA oxide is normally produced from TMA and excreted in the urine. It is likely that this oxide would account for more of the choline. Feeding such a large amount of the choline is probably saturating the capacity for metabolism and much of the choline may remain unchanged.

The present study provides further understanding of the production and excretion of amines in the normal rat. The excretion of amines appears to depend on the amine precursor supplementing the diet. DMA is the major end-product when the unsupplemented diet is fed, whilst feeding choline and creatinine enhances the excretion of TMA and MMA relative to DMA.

Lecithin is absorbed in the upper small intestine and contributes little to the production of amines.

This work was supported by the Incorporated National Association of British and Irish Millers Ltd.

\section{REFERENCES}

Akesson, B. (1982). British Journal of Nutrition 47, 223-229.

Asatoor, A. M. \& Simenhoff, M. L. (1965). Biochemica Biophysica Acta 111, 384-392.

Dominguez, R. \& Pomerene, E. (1951). Proceedings of the Society of Experimental Biology and Medicine 58, 26-28.

Houstemuller, U.M. T. (1979). In Nutrition and the Brain, vol. 5, pp. 83-93 [A. Barbeau, J. Growden and

R. Wurtmann, editors]. New York: Raven Press.

Jones, J. D. \& Burnett, P. C. (1972). Clinical Chemistry 18, 280-284.

Jones, J. D. \& Burnett, P. C. (1974). Clinical Chemistry 20, 1204-1212.

Lowis, S., Eastwood, M. A. \& Brydon, W. G. (1983). Journal of Chromatography 278, $139-143$.

Marks, R., Dudley, F. \& Wan, A. (1979). Lancet i, 1106-1107.

Marks, R., Greaves, M. W., Plotty, C. \& Hartop, P. J. (1977). British Journal of Dermatology 96, $399-402$.

Mayersohn, M., Conrad, K. A. \& Achari, R. (1983). British Journal of Clinical Pharmacology 15, $227-230$.

Simenhoff, M. L. (1975). Kidney International 7 (Suppl. 3), S314-S317. 
Simenhoff, M. L., Burke, J. F., Saukkonen, J. J., Wessen, L. G. Jr \& Schaedler, R. W. (1976). Lancet ii, 818-821. Simenhoff, M. L., Saukkonen, J. J., Burke, J. F., Schaedler, R. W., Vogel, W. H., Boree, K. \& Lasker, N. (1978). Kianey International 13 (Suppl. 8), S16-S19.

Spellacy, E. \& Watts, R. W. E. (1980). Journal of Inherited Metabolic Diseases 2, 85-86.

Technicon Instruments Co. Ltd (1970). Auto Analyzer Method no. AA11-11. Basingstoke: Technicon Instruments Co. Ltd.

Watson, A. D. J., Church, D. B. \& Fairburn, A. J. (1981). American Journal of Veterinary Research 42, $1878-1883$.

Wurtman, J. J. (1979). In Nutrition and the Brain, vol. 5, pp. 73-81, [A. Barbeau, J. Growden and P. Wurtmann, editors]. New York: Raven Press. 